\title{
CONSERVATIVE TREATMENT FOR IDIOPATHIC SCOLIOSIS
}

\author{
R. A. DICKSON
}

Because idiopathic scoliosis commences and may progress during the period of spinal growth, it has been subdivided according to when it begins (James 1954); thus infantile, juvenile and adolescent types are recognised (Goldstein and Waugh 1973). While a oneyear-old baby with a 60 idiopathic thoracic curve unquestionably has infantile scoliosis, classification becomes progressively more difficult the older the child; and although a 12-year-old girl with a $90^{\circ}$ curve is an adolescent, she does not have adolescent-onset idiopathic scoliosis, as the deformity certainly started many years earlier. Furthermore, there is no clear evidence that juvenile-onset idiopathic scoliosis exists. Of James' 134 patients with thoracic scoliosis, only 16 were tentatively classified as of juvenile onset and he did not think these worth separating from the infantile group (James 1954). Such cases may well be a hangover from infancy (Mehta 1977). There is much merit therefore in considering only two categories, early-onset and lateonset (Ponseti and Friedman 1950; Figs 1 to 4). The prevalence rate, natural history and the consequences of untreated scoliosis, as well as the strategy for treatment and its efficacy, differ very considerably between early and late-onset types. Treatment for the more common and more benign late-onset case is more "standard" and will therefore be discussed first.

\section{LATE-ONSET IDIOPATHIC SCOLIOSIS}

The need for treatment. The strategy for treating idiopathic scoliosis depends principally upon the size of the deformity and its potential for progression. If the deformity is acceptable at presentation, then preservation of acceptability is the aim; this is the place of conservative management. If the deformity is unacceptable, then the objective must be to make it acceptable and keep it so; this is the aim of surgical management. In order to decide if idiopathic scoliosis needs treatment at all, the consequences of leaving it untreated must be known. It is, of course, known that scoliosis can cause significant disability, with economic implications (Dahlberg and

R. A. Dickson, MA, ChM, FRCS, Professor and Head of the Department of Orthopaedic and Traumatic Surgery. The University of Leeds

St James`s University Hospital, Leeds LS9 7TF, England.

c 1985 British Editorial Society of Bone and Joint Surgery $0301-620 \times 85 / 2013 \$ 2.00$

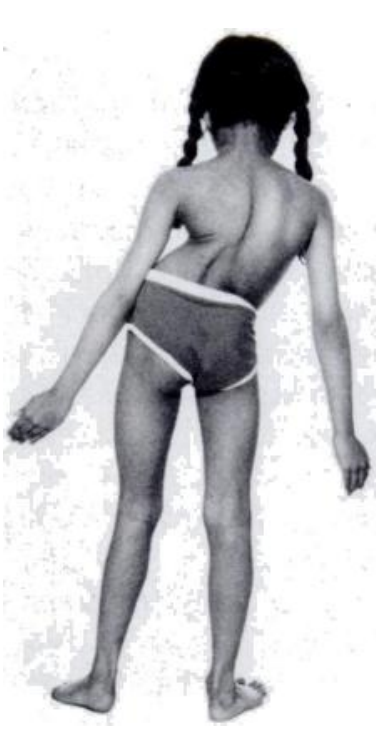

Fig. 1

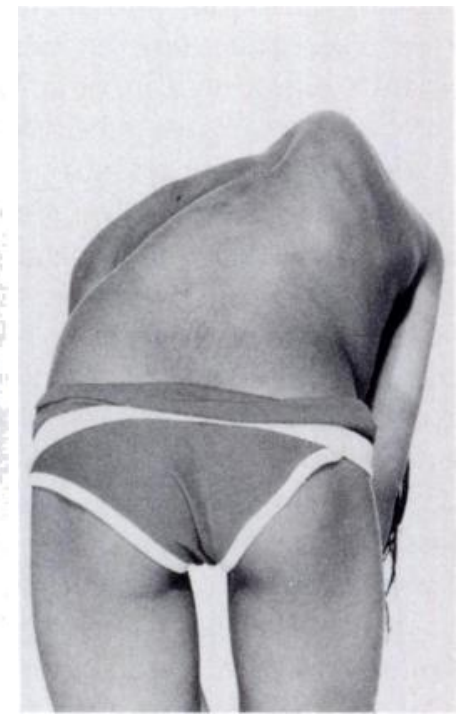

Fig. 2
Early-onset idiopathic scoliosis-a very serious condition producing cardiopulmonary compromise and horrendous deformity. Figure 1Erect. Figure 2-Close-up in the forward-bending position.

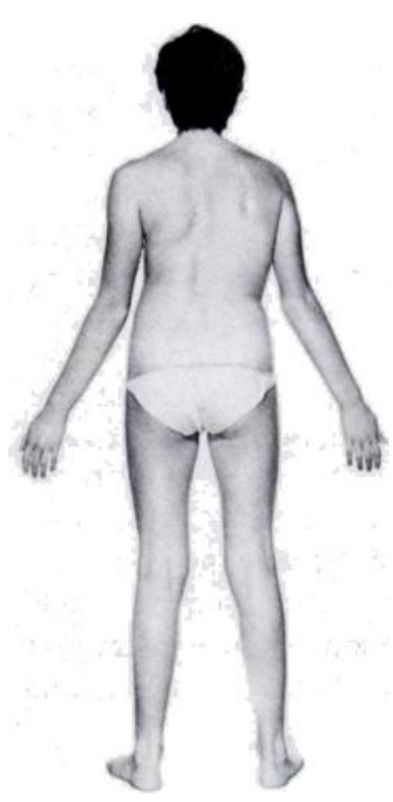

Fig. 3

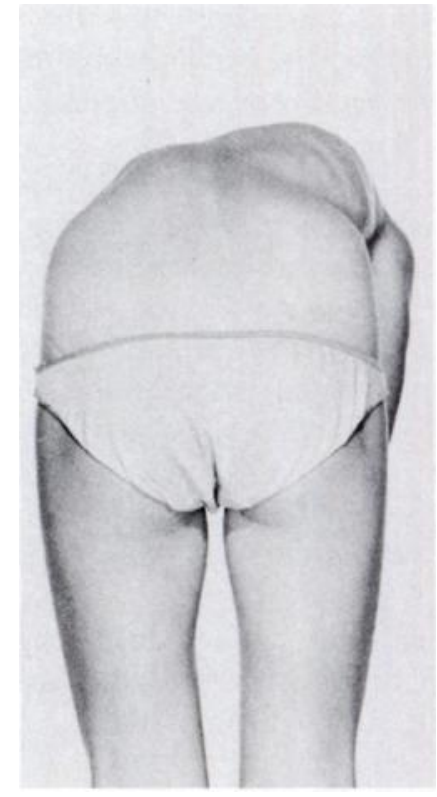

Fig. 4
Late-onset idiopathic scoliosis-a problem of deformity only. Figure 3-Erect. Figure 4-Close-up in the forward-bending position. 
Nachemson 1977), and that the cardiopulmonary complications can be a source of morbidity and mortality (Nachemson 1968; Nilsonne and Lundgren 1968; Collis and Ponseti 1969). But this applies only to early-onset cases: and then only to severe ones, for example, a thoracic curve of over 60 by the age of seven or eight years, when the pulmonary parenchyma is developing (Davies and Reid 1971).

In contradistinction there are no obvious organic consequences of late-onset idiopathic scoliosis, even if the deformity exceeds 100 (Kostuik, Israel and Hall 1973; Ponder et al. 1975; Dickson and Leatherman 1976). Late-onset idiopathic scoliosis is a problem of deformity only. The 52 late-onset idiopathic cases in Nachemson's original study of 130 patients fared no differently from their straight-backed counterparts as regards organic health (Nachemson 1968). With regard to the deformity, it is of course true that the bigger the deformity the greater the likelihood of social and psychological implications (Nilsonne and Lundgren 1968: Bengtsson et al. 1974). The patient's opinion on this subject clearly matters more than that of the surgeon.

Natural history. As there has never been a controlled trial of conservative treatment its efficacy can only be determined by evaluating it against the little we know of the natural history of the late-onset curve. There are two quite different sources of information. Early studies of selected groups of children who presented to scoliosis clinics suggested a considerable progression potential if the onset was under 10 years of age or before the menarche (Risser and Ferguson 1936; Ponseti and Friedman 1950; James 1954; Heine and Reher 1975). More recent data come from those school screening programmes which have included a longitudinal survey (Brooks et al. 1975; Rogala, Drummond and Gurr 1978; Dickson et al. 1980; Dickson 1983). When children with non-structural curves are excluded, only $10 \%$ show evidence of progression, whereas twice as many improve and more than two-thirds remain static. The greatest progression potential is associated with the young girl who has a right thoracic curve, but she represents less than one in a thousand of those screened. The difference between the data from these two sources, although difficult to interpret (Leaver, Alvik and Warren 1982), suggests a change to a more benign natural history, and this is supported by the observation that where a lot of screening has been performed the need for both conservative and operative management has been much less (Lonstein et al. 1982). Conservative treatment should then be set against this background. Three conservative methods need to be discussed: bracing. casting and electrospinal stimulation.

Brace treatment. While various contraptions for the scoliotic spine have been used since the time of Hippocrates, real enthusiasm for conservative treatment started with the Milwaukee brace (Blount and Schmidt
1957; Blount 1958). Newer technology refers to this brace as a CTLSO (cervical-thoracic-lumbar-sacral orthosis) (Nash 1980). Although the brace was not primarily intended for the conservative management of idiopathic scoliosis, it was soon used for that purpose (Blount 1972; Moe 1973). Early mechanical studies suggested that the brace might function by exerting distraction between the head and the pelvis (Schultz and Galante 1969; Galante et al. 1970) and this mode of action was corroborated by the harmful effects on dentition thereby produced (Alexander 1966). A change to the throat mould type of brace led to a great reduction in the distraction force with no obvious dental problems (Northway, Alexander and Riolo 1974); and a change in biomechanical approach led to three-point fixation with particular emphasis placed on the localiser pad (Andriacchi et al. 1976).

Without a clear understanding of the threedimensional nature of the deformity it would be tempting to think that the brace might work in the manner described, but this is not so. The primary deformity of idiopathic scoliosis is a lordosis at the curve apex (Adams 1882; Somerville 1952; Roaf 1966; Dickson et al. 1983, 1984) and it is rotation of this lordosis to the side which produces the secondary scoliotic deformity. An ideal of conservative treatment would then be to recreate the normal spinal shape in the sagittal plane; this, however, would imply flexion, which enhances rotation and produces an increase in the secondary scoliotic deformity. In contradistinction, the opposite deformity, the kyphosis of Scheuermann's disease, is ideally suited to conservative management, because the deformity is rotationally stable and braces which cause spinal extension produce a true physiological correction of the deformity (Bradford et al. 1974). The brace is capable, however, of producing a small temporary corrective effect in idiopathic scoliosis. Blount stressed the need for obliteration of the lumbar lordosis in the brace (Blount and Moe 1973) and this produces thoracic extension above. There is now more room for the thoracic lordosis to be accommodated with a derotation effect, but at the possible expense of increasing the primary lordosis (Winter, Lovell and Moc 1975; Figs 5 and 6). The other important effect of the brace is to splint the spine to the pelvis in the erect position which thus prevents the harmful effect of flexion.

With this mode of action it is not surprising to find that the optimal result of brace wearing is when the curve measures exactly the same at the end of treatment as it did at the beginning (Keiser and Shufflebarger 1976; Edmondson and Morris 1977; Mellencamp, Blount and Anderson 1977; Tolo and Gillespie 1978; Blount 1981). These studies also suggest that the more the curve has progressed beyond 30 before the commencement of treatment, the less satisfactorily can curve progression be attenuated, as gravity and the rigidity of the secondary deformities more successfully defeat the intentions of 


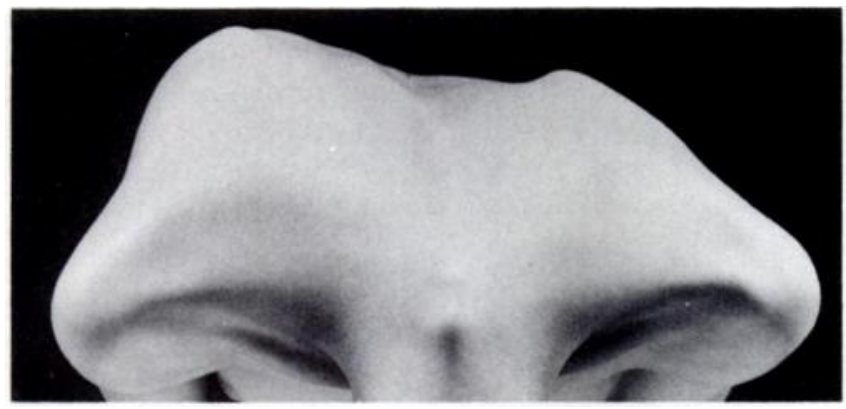

Fig. 5

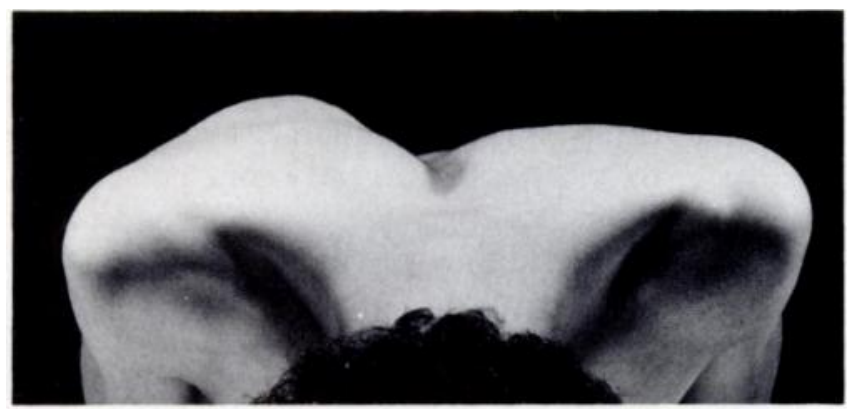

Fig. 6

The effect of obliteration of the lumbar lordosis. Figure 5-A thoracic deformity associated with a lumbar lordosis viewed from above. Figure 6-The same deformity viewed from above with the lumbar lordosis obliterated. Marked derotation has occurred.

treatment. The best results of brace treatment are therefore achieved with smaller curves; their natural history, however, demonstrates that very few would have progressed if left untreated.

The brace is supposed to be worn for 23 hours out of 24 , although it would appear to be unnecessary at night when repeated cycles of spinal flexion are not usually performed. Although exercises have no corrective effect on idiopathic curves (Stone et al. 1979), an exercise programme is prescribed for the one hour a day spent out of the brace lest the spine become unduly stiff; this programme should not, however, include flexion exercises as these will undo what the brace has been trying to achieve for the previous 23 hours.

Set against the background of natural history there is no evidence that Milwaukee brace treatment alters the course of the scoliosis. This is a very serious matter, as countless numbers of children may have endured brace treatment for no detectable benefit. If the effect of the brace on girls with progressive thoracic curves was not diluted by the inclusion of curves at other sites with little or no progression potential, then the lumbar lordosisobliterating and flexion-preventing effect of the brace ought to prevent progression (Dickson et al. 1984). Cognisant of this problem the British Orthopaedic Association and the British Scoliosis Society (1983) are right to stress the need for carefully controlled studies of idiopathic scoliosis, preferably throughout life.

It recently became apparent that low thoracic and lumbar curves did not require the full superstructure of a
Milwaukee brace (Park et al. 1977; Watts, Hall and Stanish 1977; Winter and Carlson 1977); this is because flexion of these low curves can be prevented even by an underarm brace, TLSO (thoracic-lumbar-sacral orthosis). But the other mode of action, obliteration of the lumbar lordosis, is more obvious and produces a bigger temporary corrective effect. There are no controlled trials with an underarm brace and the follow-up is much shorter than with a Milwaukee brace; consequently their efficacy also is questionable, though of course their lighter weight and smaller size make them more acceptable to the patient.

Another problem concerns the duration of spinal growth. The only period after the intra-uterine phase when growth velocity increases is during the adolescent growth spurt, which is maximal at about the age of 12 years in girls and 14 in boys (Scammon 1927). While idiopathic curves are particularly liable to deteriorate during this phase, general skeletal maturity is reached two years later (Tanner 1962). The conventional time when the patient is weaned from the brace has been when the iliac crest and vertebral ring apophyses fuse (Risser and Ferguson 1936; James 1954; Risser 1964). It is well known, however, that spinal growth continues for a further 10 years until the vertebral epiphyses are fused and that the vertebral apophyses have nothing whatever to do with spinal growth nor does their fusion indicate cessation of growth (Bick, Copel and Spector 1950; Bick and Copel 1951; Inkster 1951; Calvo 1957; Tupman 1962; Larsen and Nordentoft 1962; Bernick and Caillet 1982). Recent studies of idiopathic curves beyond general skeletal maturity do, in fact, demonstrate progression in the majority of cases (Hassan and Bjerkreim 1983; Weinstein and Ponseti 1983). While these studies have suggested that the effect of pregnancy on ligaments might be a responsible factor, it ought not to be forgotten that, in young women, the spine is still growing. Even if there was evidence that the brace did prevent progression, treatment would need to be continued for much longer than the patient would tolerate.

Cast management. The pioneers of the treatment of scoliosis obtained correction by using plaster casts (Risser et al. 1953; Risser 1955) and it was remarkable to what good use they put them (Moe and Valuska 1966). With the advent of the Milwaukee brace, enthusiasm for plaster in the conservative treatment rapidly waned in many parts of the world. French surgeons, however, did not lose their faith in plaster techniques and have developed the EDF (elongation-derotation-flexion) cast as an alternative to brace treatment (Cotrel and Morel 1964). The function of this cast is precisely that of the brace, with obliteration of the lumbar lordosis and elimination of spinal flexion as the two priorities. Each cast is worn for three or four months until its wear or the patient's growth indicates that a new one is required. The patients cannot bathe, but it is extraordinary how easy it is to change the inner vest and the underwear while the 
cast is in place. Furthermore, the cast has a window on the concave side posteriorly and one on the convex side anteriorly; these facilitate derotation exercises and allow pressure pads or balloons to be inserted over the rotational prominences. Since the object of conservative treatment is to finish up with the least deformed torso, "bracers" would do well to compare their end-results with French "casters" although, as with the majority of interesting questions, the answer has never been elucidated by a controlled study. Between casts a programme of non-skeletal traction and exercises is carried out (Cotrel and D'Amore 1968). This is of no benefit, however, in terms of curve correction (Nachemson and Nordwell 1977; Dickson and Leatherman 1978). Indeed, traction of any kind provides no real correction of curves of any magnitude, only moving each curve through its natural range of flexibility (Edgar, Chapman and Glasgow 1982).

Electrospinal stimulation. Recently, attention has been directed towards obtaining temporary correction of the scoliosis by electrical stimulation of the spinal musculature on the convexity of the curve (Bobechko 1974). Like the development of orthotic and cast treatment, electrical stimulation focuses on the secondary coronal-plane deformity and only moves the spine within its natural range of elasticity. Furthermore, electrical stimulation stemmed from the belief that there was a neuromuscular basis to the deformity, a belief which is unlikely to be substantiated (Dickson et al. 1984).

The fact that mild coronal-plane curvatures in animals can be produced by stimulating muscles on one side (Olsen et al. 1975; Monticelli et al. 1975; Bobechko, Herbert and Friedman 1976) is not surprising. This is precisely what happens when someone with a straight spine bends to one side and then resumes the erect position. Some improvement in curve magnitude has been demonstrated during convex muscle stimulation (Bobechko, Herbert and Friedman 1979); this demonstrates the innate flexibility that the mild idiopathic curve enjoys, but there is no evidence that any real correction follows electrospinal stimulation (Axelgaard and Brown 1983). Again it is the rotationally unstable nature of the primary lordotic deformity which militates against effective conservative treatment; with the uniplanar and rotationally stable kyphotic deformity, however, electrical surface stimulation can, like the brace or cast, give rise to permanent correction (Axelgaard, Brown and Swank 1982).

\section{EARLY-ONSET IDIOPATHIC SCOLIOSIS}

Natural history. This fascinating condition, first reported from Holland (Harrenstein 1929), tends to affect children from birth to three years of age. Boys are affected more commonly than girls and thoracic curves are more frequently convex to the left (James 1951; James, LloydRoberts and Pilcher 1959; Lloyd-Roberts and Pilcher 1965: Wynne-Davies 1975; Thompson and Bentley
1980). Here progression potential is particularly relevant. It was first thought that the condition could be divided into two types-progressive and resolving-depending upon the size of the rib-vertebra angle difference (RVAD; Mehta 1972). The picture is not so clear, however, and three types are now recognisedprogressive, static and resolving (Mehta 1977). While an RVAD of less than 20 which then reduces in magnitude confidently diagnoses the resolving curve, an RVAD in excess of 20 or one that is increasing does not necessarily imply a progressive curve. Other factors also are important. Thoracic and thoracolumbar curves and small initial curves (Mehta 1977; Thompson and Bentley 1980) tend to resolve, while double structural curves have a definite progression potential (Ceballos et al. 1980). The most serious progression appears to occur in the hypotonic, low birth weight baby in whom the condition has been referred to as "malignant" idiopathic scoliosis (Mehta 1977).

A very interesting trend has emerged over the last 35 years. Early reports indicated a great preponderance of the progressive type of curve (James 1951; Scott and Morgan 1955; James et al. 1959), but this situation then changed dramatically and the last 20 years has seen a marked reversal of the proportions with $90 \%$ or more resolving (Lloyd-Roberts and Pilcher 1965; Mau 1968; Thompson and Bentley 1980; Ceballos et al. 1980). The incidence of these infantile curves also has rapidly declined and the condition is now rare; whether or not this decline is due to prone lying in the cot is unclear (McMaster 1983). These changes in the natural history of early-onset progressive idiopathic scoliosis are very welcome, as these are the curves associated with serious cardiopulmonary disease at an early age, and they also develop horrifying deformities.

Conservative treatment. When malignant progressive curves were more common, treatment presented great problems. Progression potential was far too great to be attenuated by a Milwaukee brace (James et al. 1959), but posterior fusion was withheld for as long as possible in order to avoid increasing the primary lordosis; meanwhile the deformity progressed inexorably in the brace. By the time posterior fusion was performed, the deformity was often too far advanced for treatment; moreover, there is no clear evidence that fusion reduced the rate of subsequent progression (Letts and Bobechko 1974; McMaster and Macnicol 1979).

Unlike late-onset deformities there is some evidence that early-onset idiopathic scoliosis can be treated conservatively. Mehta, who has contributed much to our knowledge of infantile idiopathic scoliosis, recognised early the bad prognosis associated with the hypotonic infant, and the moment she saw such a child she applied an elongation-rotation-flexion (EDF) cast (Mehta and Morel 1979). Surprisingly, the occasional case that had all the ingredients for rapid progression appeared to become static, or even to resolve, and the RVAD became 
smaller or did not increase. This perhaps demonstrates the effect of obliteration of the lumbar lordosis and the prevention of flexion in these very supple spines; but the cast must also have allowed the thoracic spine to become naturally kyphotic in those that subsequently resolved.

There are, clearly, two important aspects of the conservative management of the early-onset case, namely, prevention and casting. Although debate continues as to whether the deformity is due to intra-uterine moulding (Browne 1936) or to positioning in the cot (Mau 1968), prone lying does appear to have an inhibitory effect; it must be insisted upon, particularly for the hypotonic infant (McMaster 1983). For the rare case that does develop an idiopathic curve with all the hallmarks of progression, serial EDF casts should be applied without delay (Mehta 1977).

\section{REFERENCES}

Adams W. Lectures on the pathology and treatment of lateral and other forms of curvature of the spine. London: J \& A Churchill \& Sons, 1882 .

Alexander RG. The effects on tooth position and maxillofacial vertical growth during treatment of scoliosis with the Milwaukee brace. Am J Orthod 1966;52: 161-89.

Andriacchi TP, Schultz AB, Belytschko TB, DeWald RL. Milwaukee brace correction of idiopathic scoliosis: a biomechanical analysis and a retrospective study. J Bone Joint Surg $[\mathrm{Am}]$ 1976:58-A: $806-15$.

Axelgaard J, Brown JC. Lateral electrical surface stimulation for the treatment of progressive idiopathic scoliosis. Spine 1983;8(3): $242-60$.

Axelgaard J, Brown JC, Swank SM. Kyphosis treatment by electrical surface stimulation. Orthop Trans 1982;6:1.

Bengtsson G, Fällström K, Jansson B, Nachemson A. A psychological and psychiatric investigation of the adjustment of female scoliosis patients. Actu Psychiatr Scand 1974:50:50-9.

Bernick S, Caillet $\mathbf{R}$. Vertebral end-plate changes with aging of the human vertebrac. Spine 1982;7(2):97-102.

Bick EM, Copel JW. The ring apophysis of the human vertebra. Contribution to human osteogeny. II. J Bone Joint Surg $[\mathrm{Am}]$ 1951:33-A:783-7.

Bick EM, Copel JW, Spector S. Longitudinal growth of the human vertebra: a contribution to human osteogeny. J Bone Joint Surg [Am] 1950:32-A:803-14.

Blount WP. Scoliosis and the Milwaukee brace. Bull Hosp Joint Dis 1958:19:152-65

Blount WP. Use of the Milwaukee brace. Orthop Clin North Am. 1972:3:3-16.

Blount WP. Editorial. The virtue of early treatment of idiopathic scoliosis. J Bone Joint Surg [Am] 1981:63-A:335-6.

Blount WP, Moe JH. The Milwaukee brace. Baltimore: Williams \& Wilkins, 1973

Blount WP, Schmidt AC. The Milwaukee brace in the treatment of scoliosis. J Bone Joint Surg [Am] 1957;39-A:693.

Bobechko WP. Scoliosis spinal pacemakers. J Bone Joint Surg $[\mathrm{Am}]$ 1974:56-A:442.

Bobechko WP, Herbert M, Friedman $H$. Electro-spinal instrumentation. J Bone Joint Surg [Am] 1976:58-A:156.

Bobechko WP, Herbert M, Friedman HG. Electrospinal instrumentation for scoliosis: current status. Orthop Clin North Am 1979:10(4): $927-41$.

Bradford DS, Moe JH, Montalvo FJ, Winter RB. Scheuermann's kyphosis and roundback deformity: results of Milwaukee brace treatment. J Bone Joint Surg [Am] 1974;56-A:740-58.

British Orthopaedic Association and the British Scoliosis Society. School screening for scoliosis. Brit Med J 1983;287:963-4.

Brooks HL, Azen SP, Gerberg E, Brooks R, Chan L. Scoliosis: a prospective epidemiological study. J Bone Joint Surg $[\mathrm{Am}]$ 1975:57-A: 968-72.
Browne D. Congenital deformities of mechanical origin. Proc $R$ Soc Med 1936:29: 1409-31.

Calvo IJ. Observations on the growth of the female adolescent spine and its relation to scoliosis. Clin Orthop 1957; 10:40-7.

Ceballos T, Ferrer-Torrelles M, Castillo F, Fernandez-Paredes E Prognosis in infantile idiopathic scoliosis. J Bone Joint Surg $[\mathrm{Am}]$ 1980:62-A:863-75.

Collis DK, Ponseti IV. Long-term follow-up of patients with idiopathic scoliosis not treated surgically. J Bone Joint Surg $[\mathrm{Am}]$ 1969; 51-A:425-45.

Cotrel Y, D'Amore M. Spinal traction in scoliosis. In: Zorab PA, ed. Proceedings of a second symposium on scoliosis: causation. Edinburgh and London: E \& S Livingstone. 1968:37-43.

Cotrel Y, Morel G. La technique de I'E.D.F dans la correction des scolioses. Rev Chir Orthop 1964:50:59-75.

Dahlberg L, Nachemson AL. The economic aspects of scoliosis treatment. In: Zorab PA, ed. Scoliosis: proceedings of a fifth symposium held at the Cardiothoracic Institute. Brompton Hospital, London, on 2lst, 22nd September, 1976. London: Academic Press, 1977:73-101.

Davies G, Reid L. Effect of scoliosis on growth of alveoli and pulmonary arteries and on right ventricle. Arch Dis Child 1971:46:623-32.

Dickson RA. Scoliosis in the community. Br Med J 1983;286:615-8.

Dickson RA, Lawton JO, Archer IA, Butt WP. The pathogenesis of idiopathic scoliosis. Biplanar spinal asymmetry. J Bone Joint Surg [Br] 1984;66-B:8-15.

Dickson RA, Lawton JO, Archer IA, et al. Combined median and coronal plane asymmetry: the essential lesion of idiopathic scoliosis. J Bone Joint Surg [Br] 1983;65-B:368.

Dickson RA, Leatherman KD. Spinal deformity in adults: changing concepts. J Bone Joint Surg [Am] 1976:58-A:729.

Dickson RA, Leatherman KD. Cotrel traction, exercises, casting in the treatment of idiopathic scoliosis: a pilot study and prospective randomized controlled clinical trial. Acta Orihop Scand 1978:49:46-8.

Dickson RA, Stamper P, Sharp A-M, Harker P. School screening for scoliosis: cohort study of clinical course. Br Med J 1980;281 265-7.

Edgar MA, Chapman RH, Glasgow MMS. Pre-operative correction in adolescent idiopathic scoliosis. J Bone Joint Surg $[B r]$ 1982; 64-B: 530-5.

Edmondson AS, Morris JT. Follow-up study of Milwaukee brace treatment in patients with idiopathic scoliosis. Clin Orthop 1977:126:58-61

Galante J, Schultz A, DeWald RL, Ray RD. Forces acting in the Milwaukee brace on patients undergoing treatment for idiopathic scoliosis. J Bone Joint Surg $[\mathrm{Am}]$ 1970:52-A:498-506.

Goldstein LA, Waugh TR. Classification and terminology of scoliosis Clin Orthop 1973:93:10-22.

Harrenstein RJ. Die Skoliose bei Säuglingen und ihre Behandlung. Z Orthop Chir 1929:52:1-40.

Hassan I, Bjerkreim I. Progression in idiopathic scoliosis after conservative treatment. Acta Orthop Scand 1983;54:88-90.

Heine J, Reher H. Die Progredienz der unbehandelten idiopathischen Skoliose bis Wachstumsabschluss. Z Orthop 1975:113 87-96.

Inkster RG. Osteology. In: Brash JC, ed. Cunningham's text-hook of anatomiv, 9th edn. London: Oxford University Press, 1951:105-331.

James JIP. Two curve patterns in idiopathic structural scoliosis. $J$ Bone Joint Surg [Br] 1951:33-B:399-406.

James JIP. Idiopathic scoliosis: the prognosis, diagnosis and operative indications related to curve patterns and the age at onset. $J$ Bone Joint Surg [Br] 1954:36-B: 36-49.

James JIP, Lloyd-Roberts GC, Pilcher MF. Infantile structural scoliosis. J Bone Joint Surg [Br] 1959:41-B:719-35.

Keiser RP, Shufflebarger HL. The Milwaukee brace in idiopathic scoliosis: evaluation of 123 completed cases. Clin Orthop 1976:118:19-24.

Kostuik JP, Israel J, Hall JE. Scoliosis surgery in adults. Clin Orıhop 1973:93:225-34.

Larsen EH, Nordentoft EL. Growth of the epiphyses and vertebra. Acta Orthop Scand 1962:32:210-7.

Leaver JM, Alvik A, Warren MD. Prescriptive screening for adolescent idiopathic scoliosis: a review of the evidence. Int J Epidemiol 1982:11(2): 101-11 
Letts RM, Bobechko WP. Fusion of the scoliotic spine in young children: effects on prognosis and growth. Clin Orthop $1974: 101: 136-45$.

Lloyd-Roberts GC, Pilcher MF. Structural idiopathic scoliosis in infancy: a study of the natural history of 100 patients. $J$ Bone Joint Surg $[\mathrm{Br}]$ 1965;47-B:520-3

Lonstein JE, Bjorklund S, Wanninger MH, Nelson RP. Voluntary school screening for scoliosis in Minnesota. J Bone Joint Surg $[\mathrm{Am}]$ 1982:64-A:481-8.

McMaster MJ. Infantile idiopathic scoliosis: can it be prevented? $J$ Bone Joint Surg [Br] 1983;65-B:612-7.

McMaster MJ, Macnicol MF. The management of progressive infantile idiopathic scoliosis. J Bone Joint Surg [Br] 1979:61-B:36-42.

Mau H. Does infantile scoliosis require treatment? $J$ Bone Joint Surg [Br] 1968:50-B:881.

Mehta MH. The rib-vertebra angle in the early diagnosis between resolving and progressive infantile scoliosis. J Bone Joint Surg $[\mathrm{Br}]$ 1972:54-B: $230-43$.

Mehta MH. The natural history of infantile idiopathic scoliosis. In: Zorab PA, ed. Scoliosis: proceedings of a fifth symposium held at the Cardiothoracic Institute, Brompton Hospital. London, on 21st. 22nd September, 1976. London: Academic Press, 1977: 103-22.

Mehta MH, Morel G. The non-operative treatment of infantile idiopathic scoliosis. In: Zorab PA, Siegler D, eds. Scoliosis 1979. Based on the proceedings of the sixth symposium on scoliosis held at the Cardiothoracic Institute. Brompton Hospital, London, on September 17 and 18, 1979. London: Academic Press, 1980:71-84.

Mellencamp DD, Blount WP, Anderson AJ. Milwaukee brace treatment of idiopathic scoliosis: late results. Clin Orthop 1977:126:47-57.

Moe JH. Indications for Milwaukee brace non-operative treatment in idiopathic scoliosis. Clin Orthop 1973;93:38-43.

Moe JH, Valuska J. Evaluation of treatment of scoliosis by Harrington instrumentation. J Bone Joint Surg $[\mathrm{Am}]$ 1966:48-A : 1656-7.

Monticelli G, Ascani E, Salsano V, Salsano A. Experimental scoliosis induced by prolonged minimal electrical stimulation in the paravertebral muscles. Ital J Orthop Traumatol 1975:1:39-54.

Nachemson A. A long term follow-up study of non-treated scoliosis. Acta Orthop Scand 1968:39:466-76.

Nachemson A, Nordwell A. Effectiveness of preoperative Cotrel traction for correction of idiopathic scoliosis. J Bone Joint Surg $[\mathrm{Am}]$ 1977:59-A:504-8.

Nash CL Jr. Current concepts review: scoliosis bracing. J Bone Joint Surg $[\mathrm{Am}]$ 1980;62-A:848-52.

Nilsonne U, Lundgren K-D. Long-term prognosis in idiopathic scoliosis. Acta Orthop Scand 1968:39:456-65.

Northway RO Jr, Alexander RG, Riolo ML. A cephalometric evaluation of the old Milwaukee brace and the modified Milwaukee brace in relation to the normal growing child. Am J Orthod 1974:65:341-63.

Olsen GA, Rosen H, Stoll S, Brown G. The use of muscle stimulation for inducing scoliotic curves: a preliminary report. Clin Orthop 1975:113:198-211.

Park J, Houtkin S, Grossman J, Levine DB. A modified brace (Prenyl) for scoliosis. Clin Orthop 1977:126:67-73.

Ponder CR, Dickson JH, Harrington PR, Erwin WD. Results of Harrington instrumentation and fusion in the adult idiopathic scoliosis patient. J Bone Joint Surg [Am] 1975:57-A:797-801.
Ponseti IV, Friedman B. Prognosis in idiopathic scoliosis. J Bone Joint Surg [Am] 1950:32-A:381-95.

Risser JC. Scoliosis: the application of body casts for the correction of scoliosis. Am Acad Orthop Surg Instruct Course Lect 1955:12: 255-9.

Risser JC. Scoliosis: past and present. J Bone Joint Surg [Am] 1964 ; 46-A : 167-99.

Risser JC, Ferguson AB. Scoliosis: its prognosis. J Bone Joint Surg 1936; 18:667-70.

Risser JC, Lauder CH, Norquist DM, Craig WA. Three types of body casts. Am Acad Orthop Surg Instruct Course Lect 1953;10:131-42.

Roaf R. The basic anatomy of scoliosis. J Bone Joint Surg [Br] 1966; 48-B: 786-92.

Rogala EG, Drummond DS, Gurr J. Scoliosis: incidence and natural history: a prospective epidemiological study. J Bone Joint Surg [Am] 1978:60-A:173-6.

Scammon RE. The first seriatim study of human growth. Am J Phy: Anthropol 1927;10:329-36.

Schultz AB, Galante JO. Measurement of forces exerted in the correction of idiopathic scoliosis using three-component dynamometers. Exp Mech 1969:9:419-24.

Scott JC, Morgan TH. The natural history and prognosis of infantile idiopathic scoliosis. $J$ Bone Joint Surg [Br] 1955;37-B:400-13.

Somerville EW. Rotational lordosis: the development of the single curve. J Bone Joint Surg [Br] 1952;34-B:421-7.

Stone B, Beekman C, Hall V, Guess V, Brooks HL. The effect of an exercise program on change in curve in adolescents with minimal idiopathic scoliosis: a preliminary study. Phys Ther 1979:59: 759-63.

Tanner JM. Growth at adolescence with a general consideration of the effects of hereditary and environmental factors upon growth and maturation from hirth to maturity. 2nd edn. Oxford: Blackwell Scientific Publications, 1962.

Thompson SK, Bentley G. Prognosis in infantile idiopathic scoliosis. $J$ Bone Joint Surg [Br] 1980;62-B:151-4.

Tolo VT, Gillespie R. The characteristics of juvenile idiopathic scoliosis and results of its treatment. J Bone Joint Surg $[\mathrm{Br}] 1978$ : 60-B: $181-8$.

Tupman GS. A study of bone growth in normal children and its relationship to skeletal maturation. J Bone Joint Surg $[\mathrm{Br}]$ 1962:44-B:42-67.

Watts HG, Hall JE, Stanish W. The Boston brace system for the treatment of low thoracic and lumbar scoliosis by the use of a girdle without superstructure. Clin Orthop 1977;126:87-92.

Weinstein SL, Ponseti IV. Curve progression in idiopathic scoliosis. $J$ Bone Joint Surg [Am] 1983;65-A:447-55.

Winter RB, Lovell WW, Moe JH. Excessive thoracic lordosis and loss of pulmonary function in patients with idiopathic scoliosis. $J$ Bone Joint Surg $[\mathrm{Am}]$ 1975:57-A:972-7.

Winter RB, Carlson JM. Modern orthotics for spinal deformities. Clin Orihop 1977:126:74-86.

Wynne-Davies R. Infantile idiopathic scoliosis: causative factors, particularly in the first six months of life. $J$ Bone Joint Surg $[B r]$ 1975:57-B: $138-41$. 